\title{
SOME EXPERIMENTS UPON THE BEHAVIOR OF SQUIRRELS. ${ }^{1}$
}

\author{
BY \\ C. S. YOAKUM. \\ From the Psychological Laboratory of the University of Chicago.
}

With Five Figures.

InTRODUCTION.

This paper presents (1) a short account of previous observations on the habits and life activities of the squirrel; (2) some experiments made to compare his simpler learning processes with those of other mammals, and (3) some preliminary tests upon his temperature sense. The squirrels under observation were Sciurus niger, or Sciurus carolinensis. Melanism and other variations are so common among squirrels that no attempt was made to determine the exact variety. ${ }^{2}$

\section{Previous Observations of Squirrel Behavior.}

The few statements made by animal observers on the habits and instincts of squirrels are by'no means in proportion to the animal's attractiveness, nor to its social nature.

The numerous varieties are found throughout a widely distributed area. ${ }^{3}$ The habitat of the squirrel in his American home extends over practically the entire continents of North and South America.

The writer wishes to acknowledge his indebtedness to Professor J. B. Watson for his close supervision of the experiments and invaluable criticism during the preparation of this paper.

${ }^{2}$ Ingersolt, Ernest, Wild Neighbors, Ch. 1. See also Batrd, S. F., in U. S. Gov. Reports of Explorations and Surveys, U. S., 1857, page 244.

${ }^{8}$ For the description of the North American varieties, see Batro, op. cit., pp. 243-348.

The Journal of Comparative Neurology and Psychology.-Vol, XIX, No. 5. 


\section{Fournal of Comparative Neurology and Psychology.}

Locally, he lives in wooded tracts and he is especially numerous where nut-bearing trees and plants abound. If we include the many varieties of this order in the statement, the squirrel may be said to make his home in burrows under the ground, among the roots of large trees, in fallen logs, and lastly in knot-holes and in nests built high up in the trees themselves. The varieties studied here are chiefly arboreal, leaving their trees only for food and water and when other exigencies demand travel.

The food of the squirrel is the "fruit and buds of the trees among which he makes his home." $\mathrm{He}$ is also, under some conditions, insectivorous and possibly carnivorous. ${ }^{4}$ That he is naturally the latter is questioned by Wesley Mills. ${ }^{5}$ Pine and spruce seeds are perhaps his most common food in northern regions, and, in general, the nuts indigenous to the region in which the species lives constitute the basis of the food supply.

Some species store food for the winter; others bury the nuts in the loose soil near where they fall, apparently depending upon the large numbers buried and their own rapid exploring ability for the recovery of nuts so hidden. Observation has not fully established this point. ${ }^{6}$ The behavior of the squirrel in carrying out the storing instinct has been interestingly described elsewhere. ${ }^{7}$ From our own observations it is found that this instinct quickly disappears under the unfavorable conditions of captivity. Experimentation is in progress to determine the means by which the squirrel, almost without error, rejects the faulty nuts and opens or buries only those that are sound.

The tree squirrel does not hibernate. Observation is, however, by no means complete regarding yearly variations in the habits and activities of all varieties.

The literature is full of allusions to the agility, the skill and the general intelligence of the squirrel. These stories and observations are principally of the anecdotal variety. Ingersoll and Mills, in the

${ }^{4}$ Geological Survey of New Jersey, v. 2, pt. 2, 1890, p. 500.

'Mrlls, Weslex, Animal Intelligence, p. 55.

'See INGgrsoll, op. cit., ch. 1.

'H. G. Schmidt quoted by W. James, Principles of Psychology, v. 2, pp. 399. 400. 
accounts cited above, give us the longest connected accounts of the habits and life of the squirrel. Their citations practically cover the published observations on the squirrel.

The literature as a whole gives a fairly accurate account of the squirrel as he is seen by the casual observer. Systematic observation and investigation of his associative processes are lacking.

Mills found that the chickeree, Sciurus hudsnnius, was highly suspicious of any trap or box set to catch him. If caught in one once or twice, he would no longer even investigate the trap. On the other hand, the chipmunk, Tamias lysteri, would enter the trap as often as he came near it. Mills considers this an evidence of the superior intelligence of the red squirrel. He makes no attempt to explain the difference in behavior upon the basis of the striking difference in the nesting habits of the animals, the former nesting in trees, the latter burrowing underground. Mills eites the observations of other writers on this point. ${ }^{8}$ Numerous scattered observations are collected by this author and by $\mathrm{E}$. Ingersoll, quoted above. We have not repeated these citations, since they are available in their present form and have little bearing upon the further investigations of this paper.

II. Some Experiments upon tihe Associative Processes of the Grey SquirReL.

1. The Method of Taming the Squirrel.-The task of taming the grey squirrel is often a difficult one. Some of the animals under observation for as long as six months failed to become entirely tame. Others, captured in semi-wild state, in parks, etc., became sufficiently tame to be used for experimentation in less than two months. The squirrel is compelled by his environment to be ever on the alert, and his arboreal habits make confinement particularly distasteful. Caging without the wheel or in small cages tends to make them weak and unhealthy. If the squirrel be supplied with hard nuts and wood upon which by gnawing he may exercise his muscles and keep his teeth at their normal length, he may be kept for long periods of time in a fairly normal condition.

${ }^{8}$ Op. cit., pp. 52 ff. 


\section{Fournal of Comparative Neurology and Psychology.}

For some time after capture the squirrel seeks always to hide. Food will not be taken for hours and then only after a searching exploration of the cage has shown escape to be impossible. The hiding consists in seeking the distant and most inaccessible portions of the cage, burrowing under shavings, paper, hay, or whatever happens to constitute the bedding in the cage. Beginning to eat does not mean that the squirrel has given up hope of escape. All wooden parts of the cage which can be reached by two rows of sharp teeth are rapidly reduced to splinters. Soon the cage either gives way under his fierce attacks, or is found invulnerable; in the latter case, the squirrel bides his time till an open cage door or a faulty lock gives him his opportunity for freedom.

One of my squirrels kept alone in a cage $4 \times 3 \times 3$ feet still preferred the greater freedom of the room after nine months of almost steady work in problem boxes, the maze, etc., and would snatch the slightest opportunity for escape from his cage. To be sure of keeping such an animal, not only the cage, but also the rooms used in experimentation must be kept always free from even small openings. The impulse for freedom is stronger than all o sers, and undoubtedly constitutes one of the best possible incentives for further experimentation. This impulse to escape from confinement remains in full vigor even after the animal is quite tame.

The squirrel can not be handled as can the white rat and others of his family. The time spent in taming him to the point where he can be touched with the hand is long and unnecessary. The squirrel is tame for many purposes long before he will allow any one actually to hold him. When he is thoroughly tamed, and can be handled, he becomes more or less unfit for experimentation, because of his too decided interest in the movements and actions of the experimenter.

To avoid both difficulties the squirrels were moved about in a small cage. This cage had a square hole, made large enough to admitt the animals easily, cut in the center of one side. Feeding the squirrel in this once or twice was sufficient to establish in him the habit of entering whenever it was brought near his living cage. The animal while being fed in this small cage was brought as near 
as possible to the experimenter in order to accustom him to the proximity of his keeper. It is only the occasional squirrel which will tame rapidly when left and fed always in the large cage where he makes his home. By this means the animal was not handled during experimentation until he accepted petting almost as a matter of course. The problem-boxes, maze, etc., were also enclosed by wire netting, which allowed the squirrels plenty of space for investigation and still confined their movements to the space of a few feet around the problem-boxes themselves.

2. Experiments with Problem-boxes.-The first tests to be deseribed are already familiar to students of animal psychology. They are of value only by reason of the fact that they afford a basis for comparing the behavinr of squirrels under given conditions with that of other animals under similar conditions. A further, incidental, point is brought out, namely, that the squirrel if kept under the proper conditions as regards handling, food, etc., becomes a subject entirely suited to the laboratory types of tests.

The problem-boxes used in this first set of tests consisted of simple latch boxes and the ra. lified Hampton Court maze.

The first box is called the "Sawdust box" the second, the "Outside latch box," the third, the "Inside latch box." In the first, the animal must scratch away sawdust until he finds an opening which leads underneath the floor of the box; a hole in the floor gives ingress to the box. The second and third boxes must be entered through a side door fastened with a latch; a spring pulls the door open when the latch is released. In the "Outside latch box" this is accomplished by simply pushing up the bar from its resting place in the socket. The bar of the "Inside latch box" is on the inside and is lifted out of its socket by pulling upon a string which hangs outside the box and near the door. ${ }^{9}$

(a) The Sawdust Problem-box.-Tests on the sawdust box and the outside latch box were completed by Miss Ethel Chamberlain and Miss Lilian Sprague, graduate students in psychology, during the Summer of $1907 .{ }^{10}$ The remainder of the experiments began

${ }^{9}$ Photographs and detailed descriptions of the boxes may be found in Watson's Animal Education, pp. 33 ff.

${ }^{10}$ In this connection, I wish to thank them for the use of their records. 
546 Tournal of Comparative Neurology and Psychology.

TABLE I.

Showing Time in Minutes for Each Successive Trial, Number of Trials and Average Time of Trials of Two animals in Learning the Sawdust Problem-Box.

\begin{tabular}{|c|c|c|c|}
\hline $\begin{array}{l}\text { No. of } \\
\text { Trial }\end{array}$ & $\begin{array}{l}\text { No. } 2 \\
\text { Male }\end{array}$ & $\begin{array}{c}\text { No. } 3 \\
\text { Female }\end{array}$ & Average \\
\hline $\begin{array}{r}1 \\
2 \\
3 \\
4 \\
5 \\
6 \\
7 \\
8 \\
9 \\
10 \\
11 \\
12 \\
13 \\
14 \\
15 \\
16 \\
17 \\
18 \\
19 \\
20 \\
21 \\
22 \\
23 \\
24 \\
25 \\
26 \\
27 \\
28 \\
29 \\
30 \\
31 \\
32 \\
33 \\
34 \\
35 \\
36 \\
37 \\
38 \\
39 \\
40 \\
41 \\
42 \\
43 \\
44 \\
45 \\
46 \\
47 \\
48 \\
49\end{array}$ & $\begin{array}{l}5.02 \\
2.33 \\
.45 \\
.98 \\
.98 \\
.51 \\
.46 \\
.46 \\
.46 \\
.66 \\
.14 \\
1.20 \\
.48 \\
.63 \\
.05 \\
.04 \\
.14 \\
.09 \\
.03 \\
.04 \\
.07 \\
.04 \\
.05 \\
.01 \\
.08 \\
.07 \\
.03 \\
.03 \\
.02 \\
.03 \\
.02 \\
.03 \\
.03 \\
.03 \\
.03 \\
.02 \\
.02 \\
.02 \\
.02 \\
.02 \\
.01 \\
.01 \\
.01 \\
.01 \\
.02 \\
.02 \\
.01 \\
.03 \\
.03\end{array}$ & $\begin{array}{r}3.50 \\
4.00 \\
1.06 \\
.65 \\
.65 \\
.70 \\
.53 \\
.06 \\
1.55 \\
.66 \\
1.03 \\
.55 \\
.41 \\
1.06 \\
.37 \\
.43 \\
.33 \\
.50 \\
.07 \\
.05 \\
.44 \\
.19 \\
.13 \\
.05 \\
.05 \\
.04 \\
.08 \\
.03 \\
.05 \\
.02 \\
.03 \\
.05 \\
.20 \\
.13 \\
.08 \\
.03 \\
.16 \\
.02 \\
.11 \\
.10 \\
.01 \\
.01 \\
.05 \\
.02 \\
.01 \\
.03 \\
.01 \\
.01 \\
.02\end{array}$ & $\begin{array}{r}4.26 \\
3.16 \\
.75 \\
.81 \\
.81 \\
.60 \\
.49 \\
.26 \\
1.10 \\
.66 \\
.58 \\
.87 \\
.44 \\
.85 \\
.21 \\
.23 \\
.23 \\
.29 \\
.05 \\
.04 \\
.25 \\
.11 \\
.09 \\
.03 \\
.06 \\
.05 \\
.05 \\
.03 \\
.03 \\
.02 \\
.02 \\
.04 \\
.11 \\
.08 \\
.05 \\
.03 \\
.09 \\
.02 \\
.06 \\
.06 \\
.01 \\
.01 \\
.02 \\
.01 \\
.01 \\
.02 \\
.01 \\
.02 \\
.02\end{array}$ \\
\hline
\end{tabular}


YoAkUM, Behavior of Squirrels.

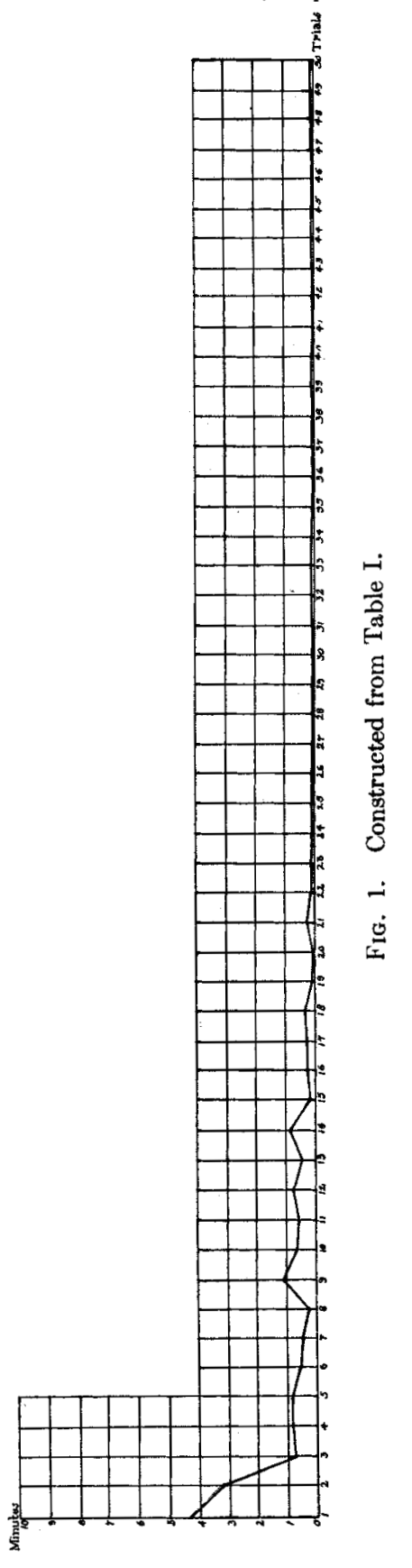




\section{$54^{8}$ Fournal of Comparative Neurology and Psychology.}

in August of that year and continued with many interruptions until August, 1908. The time allotted to each day's test, even when the work was conducted regularly, was very short and this fact accounts, in part, for the irregular number of daily tests.

The records of the learning of the sawdust box are shown in Table I; Fig. 1 shows the learning process in graphic form. The records obtained from the outside latch box are similar and are not given. Both problems are far below the ability of the animals and demand little intelligence beyond that required in the elimination of random movements.

Little need be said at this place by way of comment upon these records. The squirrel's method of solving this problem is quite similar to that of the rat. The only distinctive feature in the learning of the outside latch box was the possible use of vision and the great eagerness with which the animals directed their attack upon an apparently definite object (i.e., the bar). The food was visible through the wires of the problem-boxes and seemed on many occasions to awaken great activity by being thus visible. For example, sawdust, shavings, etc., would more often be scratched away from the side nearest the food, and at such places the fiercest and most persistent attacks were more frequently made. Such movements were made in the beginning of the experiments; as soon as the method of entering the box became in the least fixed, the food itself no longer constituted the specific incentive for making the necessary movements. All the energies of the animals were expended in getting into the box in the quickest manner possible. The problem-box could even be left empty and the squirrel would still make the run. However, unless very hungry, he could not be deceived in this way more than twice; after that the box would lose its attraction. ${ }^{11}$

(b) The Inside Latch Box.-Four animals learned this problem. Two (Nos. 1 and 4) were new to any problem of the kind, though one, No. 4, had previously learned the maze. Nos. 2 and 3 had previously learned both the sawdust box and the outside latch box. No. 1 had been in captivity six months, but had had no training of

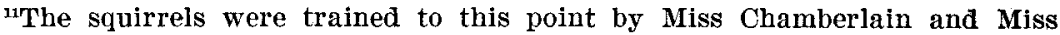
Sprague.
} 
any sort, beyond learning to run in the wheel common to squirrel cages. All were in good condition.

Table II shows the number of trials, time of each trial for each squirrel, the average time for the four animals, the average time for squirrels Nos. 2 and 3, which had been previously trained, and for the untrained animals, Nos. 1 and 4. Fig. 2 represents the last two sets of averages. $A$ is the curve for squirrels 1 and 4 , and $A B$, the curve for Nos. 2 and 3.

The two curves are strikingly dissimilar. Trials 1 and 2, of curve $\mathrm{AB}$, as shown below, are not the average trials of the two animals Nos. 2 and 3. Table II shows that at both of these trials squirrel No. 2 failed to open the problem-box. The curve AB, showing the averages of those animals that had learned the sawdust and outside latch boxes, is very irregular and does not fall below one minute until after the fourteenth trial. The curve $A$ of the two animals, which came to the problem without previous training on problemboxes of the type, is a typical learning curve. ${ }^{12}$

In all the early trials, both experienced animals were decidedly uncertain and irregular in their movements and in their mode of attack. The notes taken at this time are definite in their explanation of this difference in the learning process. The following extracts from the diary record will serve to show how the previously acquired habits were "carried over" to the new problem:

Aug. 1, '07, 12 M. Female No. 3 (trained), second trial, ran immediately to door, nosed it and then walked around box; nosed string; climbed on top of box, then off and went to south side; back to door; then back of cage; then to south side, next to door and then completely around again; scratched at bottom of cage; went to south side; next to string, nosed it and then mounted

${ }^{12}$ " $\mathrm{X}$ " in the table and curve shows where squirrel No. 4 suffered a severe fright during the night preceding the thirteenth test. A cat had been inadvertently fastened in the basement where the squirrels were kept, though not in the same room. She had evidently attempted to get out, and failing, kept up a continuous "meowing" for a large part of the night and was still making considerable disturbance in the morning. At each ery of the cat the squirrel would tremble and crouch, and frequently give the peculiar cry of a squirrel when cornered or badly frightened. The cat was removed early, but at the noon hour, though apparently recovered from fright, the squirrel made abortive and unsuccessful attempts to enter the problem-box. 
$55^{\circ}$ Tournal of Comparative Neurology and Psychology.

TABLE II.

Showing Records of Seuirrels in Iafarning Inside Iatch Box.

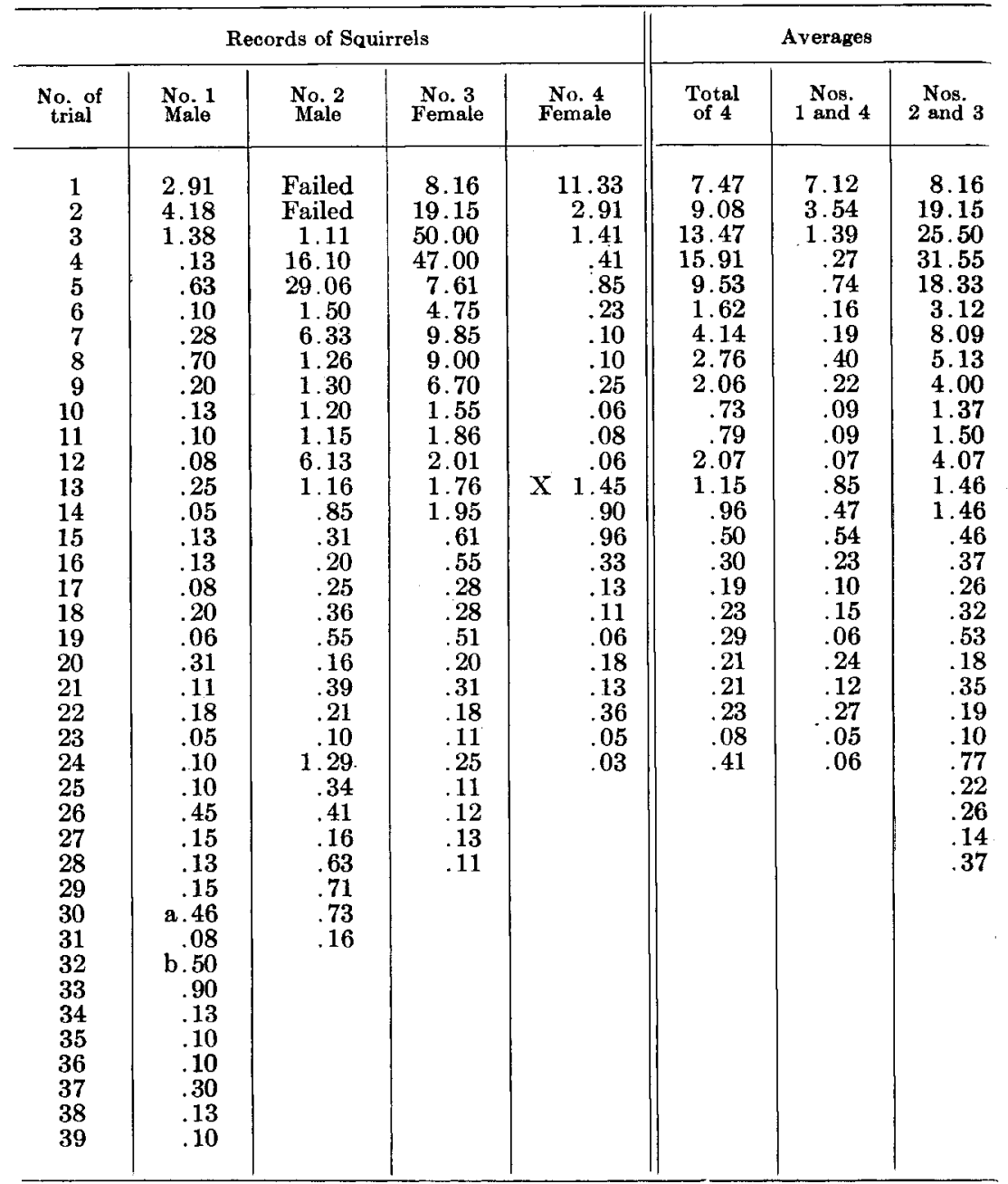

Note. At ' $a$ ' the box was turned to face in a different direction. At ' $b$ ' it was turned back to the original position. ' $X$ ' represents the effect of a definite emotional element accidentally introduced into the experiment. It is described in a note on p. 549 . 


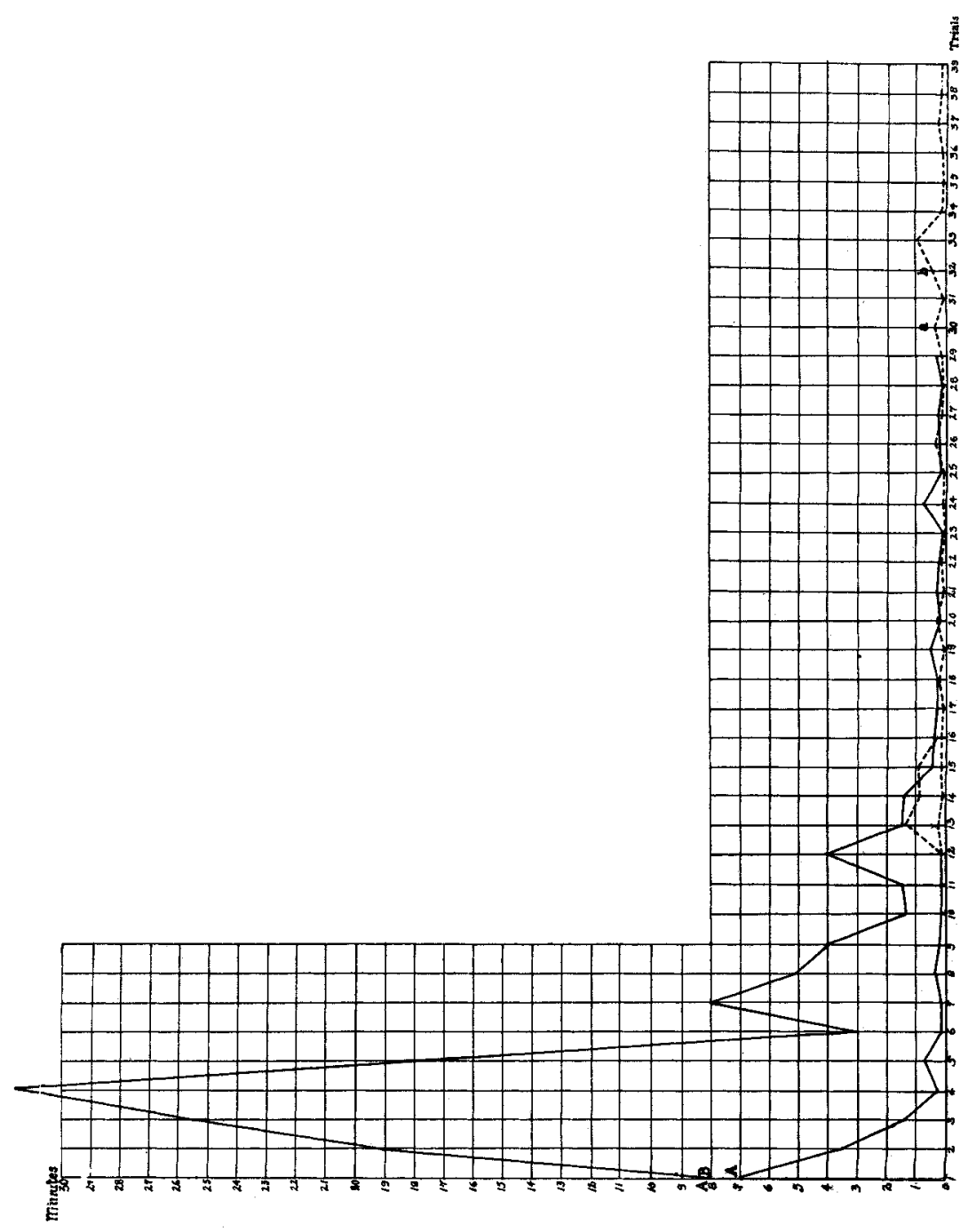

Fig. 2. Constructed from Table II. A. Curves for squirrels 1 and 4. (Previously untrained.) AB. Curve for squirrels 2 and 3. (Previously trained in "sawdust-box" and in "outside latch box.") 


\section{Fournal of Comparative Neurology and Psychology.}

to top of cage; tried to open door from top of box; climbed off box, tried door, went completely around box and worked at door again; thence to south side, and back to door and then around box again. Finally left problem-box. Climbed back on top, then off over string and to door; went back on top once more, bit at wire netting of cage enclosing problem-box; went around north side, and then back to box; nosed string; played with string, then came to south side, tried door, sat and gnawed at wood for two minutes. Stopped; ran around cage several times and went to door again; bit at nail in corner of box; then climbed on top, pulled and bit at string while there until the door came open. Did not notice that door was open and continued to tear at string and pull and tug at wire netting for one minute. Entered, time: 19-15 min.

Aug. 1, '07, 12 M. Male No. 2 (trained), second trial: Sratched at north side; at back; ran on top, down to south side; looked around; drank water out of a vessel in corner of large cage; ran over top of box and scratched at door; worked very hard here for almost a minute; scratched at north side. Pulled and tugged at wire netting on top of cage near the point where string was passed through; examined floor of large cage and scratched at door of problem-box; ran around box, listened, ran around again, listened; scratched at door and then at south corner, listened, etc. Stopped work after 61 minutes and refused to start again.

Squirrel No. 1, male (untrained), second trial: Touched door with nose, and then ran around box; ran over top of box; repeated this five or six times, trying door each time as be passed it. At intervals would run all over large cage. No scratching or working at door, simply touched it or tried to enter, as if door were open. Time: 4.18 minutes.

Squirrel No. 4, female (untrained), second trial: Ran around box, then over it five or six times; tried door twice; touched string several times in running over the box; pulled string, gave two tugs; opened it and jumped from box and ran into food. Time: 2.91 minutes.

It will be seen from these notes that the trained squirrels Nos. 2 and 3 both attempted to enter by biting and scratching at the door and by seratching sawdust, sticks and shavings away from the bottom of the problem-box on all four sides. The movements throughout were evidently those of the early learning processes. The notes also show individual differences quite plainly. Both had learned the two boxes, the sawdust and outside latch boxes. The tendency of No. 3, the female, was to bite and scratch at the door as she had done in learning the outside latch problem. In her work there was very little and, after a few slight attempts, no scratching of the sawdust at the bottom of the box. On the other hand, the male did not carry over the movements learned in his work upon 
the outside latch box, but did carry over scratching and gnawing movements acquired in the sawdust box. Both animals apparently found the task of breaking the habits acquired in the one or the other of the earlier experiments almost insuperable. The slightest noise or movement in the room, or the failure on their part to raise the lateh at the first pull on the string, would invariably drive them to use some one or more of these previously acquired movements.

The work of the untrained squirrels, Nos. 1 and 4, was of a much different type. "Useless" movements were as much in evidence, and their activity was at all times as great as that of Nos. 2 and 3. However, the movements of 1 and 4 were random movements, "useless" in the sense of not getting the animal nearer its food, and further "useless" since they did not carry out any one particular line of attack, as did the movements of squirrels Nos. 2 and 3. Pulling the string, biting at the wire, running over the box, etc., were random activities directed toward food. The scratching and steady work at the door by the trained animals constituted an activity which the most casual observer would judge to be directed toward effecting a definite mode of entrance to the food box.

An interesting point in learning to attend to the string came out in the work of all four animals. At first, the string went unnoticed or was subjected to the least possible scrutiny and the first pulling was entirely accidental. At the seventh, elghth and ninth trials, the string itself was singled out and became the point of the most eager attack. When found, it was subjected to the severest kind of strains. Hemp string no longer withstood their attacks and had to be replaced by electric light cord, and finally by flexible steel wire. The association between the string and the food supply had become definite, but the movements used in pulling the string had not yet become automatic. After the ninth and tenth trials, the unnecessary time and energy spent on the string were gradually eliminated, until finally a single pull on the string became the cue for a rush to the door. Frequently in later trials, this pull was made so hastily that it failed to open the door.

(c) The Maze.--The method of conducting the experiments on the maze is practically a repetition of that adopted in work upon the 
TABLE III.

Showing Individual and Average Time of Successive Trials in the Maze. (Two Animals.)

\begin{tabular}{|c|c|c|c|}
\hline $\begin{array}{l}\text { No. of } \\
\text { Trial }\end{array}$ & $\begin{array}{c}\text { No. I } \\
\text { Male } \\
\text { Minutes }\end{array}$ & $\begin{array}{c}\text { No. IV } \\
\text { Female } \\
\text { Minutes }\end{array}$ & Average \\
\hline $\begin{array}{r}1 \\
2 \\
3 \\
4 \\
5 \\
6 \\
7 \\
8 \\
9 \\
10 \\
11 \\
12 \\
13 \\
14 \\
15 \\
16 \\
17 \\
18 \\
19 \\
20 \\
21 \\
22 \\
23 \\
24 \\
25 \\
26 \\
27 \\
28 \\
29 \\
30 \\
31 \\
32 \\
33 \\
34 \\
35 \\
36 \\
37 \\
38 \\
39 \\
40 \\
41 \\
42 \\
43 \\
44 \\
45 \\
46 \\
47 \\
48 \\
49 \\
50\end{array}$ & $\begin{array}{r}29.00 \\
10.25 \\
9.56 \\
4.75 \\
6.33 \\
3.14 \\
1.22 \\
1.19 \\
2.83 \\
1.91 \\
1.45 \\
.67 \\
.85 \\
.58 \\
.43 \\
* 4.00 \\
.29 \\
1.40 \\
.56 \\
.60 \\
.45 \\
.60 \\
.45 \\
.98 \\
.33 \\
.86 \\
.80 \\
.66 \\
.41 \\
.80 \\
.51 \\
.26 \\
.34 \\
.40 \\
.23 \\
.22 \\
.50 \\
.35 \\
.50 \\
.36 \\
.50 \\
.40 \\
.21 \\
.23 \\
.23 \\
.30 \\
.25 \\
.35 \\
.48 \\
.35\end{array}$ & $\begin{array}{r}1.25 \\
3.80 \\
1.86 \\
1.05 \\
2.50 \\
1.83 \\
1.86 \\
.70 \\
1.08 \\
.65 \\
.38 \\
.81 \\
.83 \\
.61 \\
.66 \\
.55 \\
.61 \\
.56 \\
.45 \\
.55 \\
.45 \\
.63 \\
.36 \\
.38 \\
.28 \\
.26 \\
.26 \\
.26 \\
.25 \\
.50 \\
.28 \\
.25 \\
.26 \\
.25 \\
.25 \\
.28 \\
.26 \\
.30 \\
.26 \\
.26 \\
.25 \\
.26 \\
.28 \\
.28 \\
.28 \\
.26 \\
.40 \\
.35 \\
.28 \\
.28\end{array}$ & $\begin{array}{r}15.12 \\
7.02 \\
5.71 \\
2.80 \\
4.41 \\
2.48 \\
1.54 \\
.94 \\
1.95 \\
1.28 \\
.91 \\
.74 \\
.84 \\
.59 \\
.54 \\
2.27 \\
.45 \\
.98 \\
.50 \\
.57 \\
.45 \\
.61 \\
.41 \\
.68 \\
.30 \\
.56 \\
.53 \\
.46 \\
.33 \\
.65 \\
.39 \\
.25 \\
.30 \\
.32 \\
.24 \\
.25 \\
.38 \\
.32 \\
.38 \\
.31 \\
.36 \\
.33 \\
.24 \\
.25 \\
.25 \\
.28 \\
.32 \\
.35 \\
.38 \\
.31\end{array}$ \\
\hline
\end{tabular}

* No particular reason can be found for the high record of squirrel No. 1 in the 16 th trial. All the conditions were as usual, the animal simply stopped in the maze. No errors. 
YoAKUM, Behavior of Squirrels.

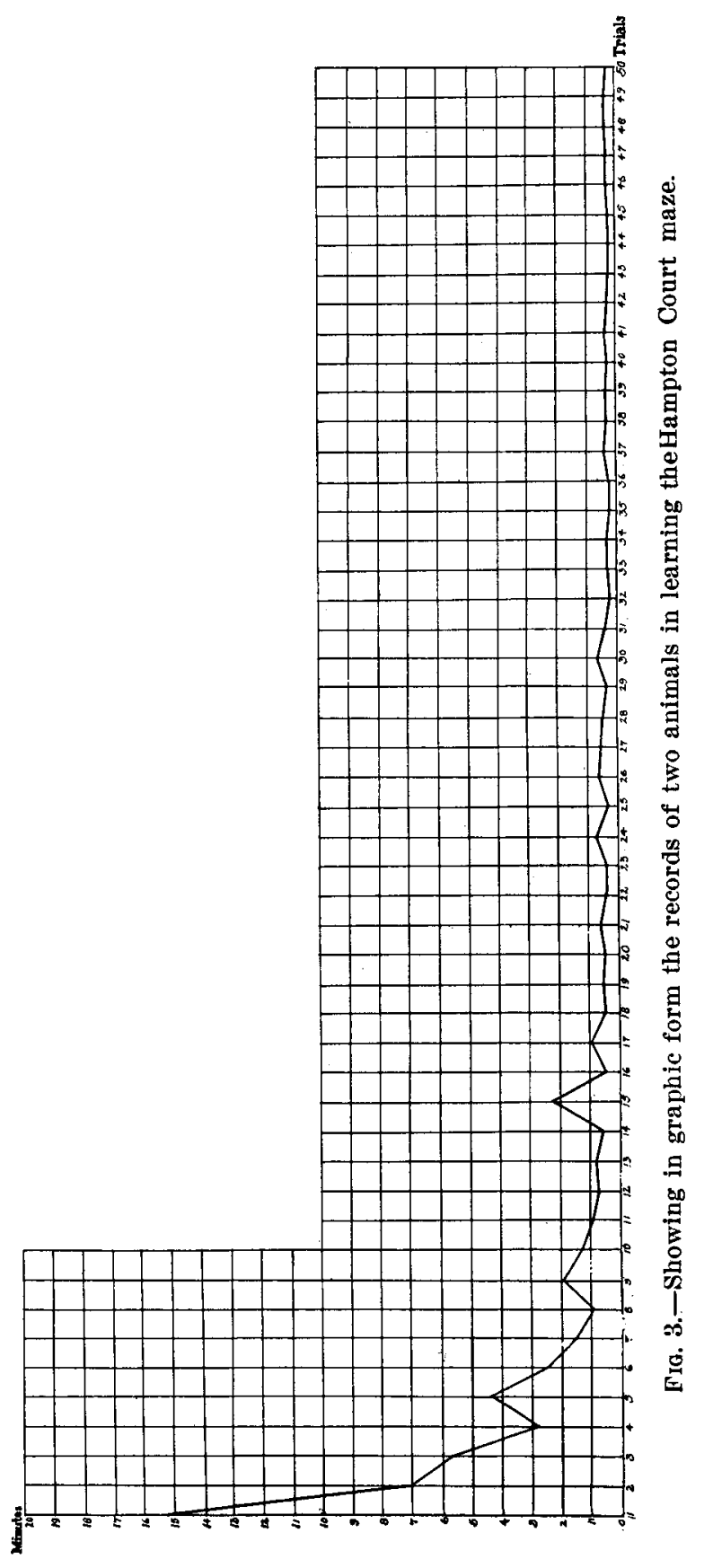




\section{$55^{6}$ Fournal of Comparative Neurology and Psychology.}

white rat. The Hampton Court maze used in the preliminary rat experiments at the Chicago laboratory was employed in this test. ${ }^{13}$ It was covered with wire netting. The food box was so arranged that the animal could be transferred to the entrance by means of a small control page described above (p. 544). A sliding trap door was inserted in the passageway just in front of the last turn which led to the food box. This was left open during the running of the maze and was closed as soon as the squirrel had entered the food compartment. Such precautions were necessary in order to prevent the return of the animal after the nut had been found or when it was desired to remove him from the food box for another trial, or to return him to his cage after the trials of the day had been completed.

The numerical results of the record are quite similar to the curve given by the learning process of the white rat. ${ }^{14}$ The accompanying table and curves show the records made by the two squirrels which learned the maze.

The process of learning the maze is for these two squirrels similar in all essential particulars to that of the rat. The early trials were characterized by all possible errors and hesitancies. Time and time again the animal would almost make the run perfectly, only to stop at the last runway and return to the starting place. The elimination of errors was fairly gradual with certain persistent errors lasting in both animals until as late as the twentieth trial.

One point was noticed which seems worthy of mention. The animals, even after having completely learned the maze, were easily disturbed. The slightest movement on the part of the observer, any noise outside of the room, or a bright beam of sunlight on any part of the maze, all must be investigated before the squirrel would continue. The hungriest squirrel could be stopped at any place in the runway and made to turn into a cul-de-sac or to go back to the starting point by moving the finger along the wire netting above him. If the observer happened to appear anywhere within the squir-

${ }^{13}$ See Warson, J. B., Kinæsthetic and Organic Sensations: their Rôle in the Reactions of the White Rat to the Maze, p. 10.

${ }^{14} \mathrm{Cf}$. Watson, op. cit., appendix. 
TABLE IV.

Showing Effect of Darkening Maze and of Rotating Maze.

\begin{tabular}{|c|c|c|c|}
\hline $\begin{array}{c}\text { No. of } \\
\text { Trial }\end{array}$ & $\begin{array}{c}\text { Male } \\
\text { Minutes }\end{array}$ & $\begin{array}{c}\text { Female } \\
\text { Minutes }\end{array}$ & Average \\
\hline \multicolumn{4}{|c|}{ Total Darkness } \\
\hline $\begin{array}{r}1 \\
2 \\
3 \\
4 \\
5 \\
6 \\
7 \\
8 \\
9 \\
10 \\
11 \\
12 \\
13 \\
14\end{array}$ & $\begin{array}{l}.38 \\
.26 \\
.30 \\
.26 \\
.30 \\
.31 \\
.58 \\
.45 \\
.30 \\
.28 \\
.26 \\
.30 \\
.28 \\
.28\end{array}$ & $\begin{array}{r}.52 \\
.41 \\
.33 \\
1.40 \\
.45 \\
.53 \\
.53 \\
.45 \\
.95 \\
.35 \\
.43 \\
.41 \\
.36 \\
.30\end{array}$ & $\begin{array}{l}.45 \\
.33 \\
.31 \\
.83 \\
.37 \\
.42 \\
.55 \\
.45 \\
.62 \\
.31 \\
.34 \\
.35 \\
32 \\
.29\end{array}$ \\
\hline \multicolumn{4}{|c|}{ Lights on } \\
\hline 15 & .28 & .36 & .32 \\
\hline 16 & .25 & .30 & .27 \\
\hline 17 & .26 & .31 & .28 \\
\hline 18 & .26 & .30 & .28 \\
\hline 19 & .26 & .30 & .28 \\
\hline 20 & \multirow{2}{*}{\multicolumn{3}{|c|}{ Maze turned $180^{\circ}$}} \\
\hline 21 & & & .71 \\
\hline 22 & 1.05 & .66 & .85 \\
\hline 23 & .31 & .61 & .46 \\
\hline 24 & 1.05 & .46 & .75 \\
\hline 25 & .38 & .33 & .35 \\
\hline 26 & .36 & .25 & .31 \\
\hline $\begin{array}{l}27 \\
28\end{array}$ & $\begin{array}{l}.31 \\
.38\end{array}$ & & \\
\hline 29 & .30 & & \\
\hline 30 & .28 & & \\
\hline $\begin{array}{l}31 \\
32\end{array}$ & $\begin{array}{l}.41 \\
.46\end{array}$ & & \\
\hline 33 & 33 & & \\
\hline 34 & .30 & & \\
\hline $\begin{array}{l}35 \\
36\end{array}$ & .28 & & \\
\hline $\begin{array}{l}36 \\
37\end{array}$ & $\begin{array}{l}25 \\
26\end{array}$ & & \\
\hline 38 & .25 & & \\
\hline \multicolumn{4}{|c|}{ Maze turned $270^{\circ}$} \\
\hline 1 & 3.25 & .57 & 1.91 \\
\hline 2 & .30 & .46 & .38 \\
\hline 3 & .60 & .30 & .45 \\
\hline 4 & .28 & .26 & .27 \\
\hline 5 & .28 & .25 & .27 \\
\hline 6 & .40 & .28 & .34 \\
\hline $\begin{array}{l}7 \\
8\end{array}$ & $\begin{array}{l}.30 \\
.28\end{array}$ & .36 & .33 \\
\hline \multicolumn{4}{|c|}{ Maze turned $360^{\circ}$} \\
\hline 1 & .33 & .33 & .33 \\
\hline 2 & .38 & .26 & .32 \\
\hline 3 & .30 & .83 & .56 \\
\hline 4 & .35 & .33 & .34 \\
\hline $\begin{array}{l}5 \\
6\end{array}$ & & .52 & \\
\hline 7 & & .38 & \\
\hline 8 & & .36 & \\
\hline
\end{tabular}




\section{$55^{8}$ Fournal of Comparative Neurology and Psychology.}

rel's field of vision, the animal would stop a moment and look up, or try to get out, at the place nearest the observer. Timidity also often produced hesitancies and slowed the time without actually resulting in error. The actual care of the squirrel in the maze turns out to be distinctly more difficult than is the case with the white rat. The former is much more easily disturbed emotionally than the latter. Curiosity and the desire for social contact with the experimenter also often cause interruptions in the squirrel's run through the maze.

(d) Effects of Darkening the Maze and of Rotating the Maze.Table IV and Fig. 4, appended below, show the effects of darkening the maze and of rotating the maze $180^{\circ}, 270^{\circ}$, and $360^{\circ}$ on two squirrels trained to run the maze in the light.

The irregularity in the record apparently produced by the absence of the light appeared only when the light was turned out after the animals had obtained their "cue." That it is caused by distinctly emotional changes and not by a loss of "cues" due to the darkness, follows from the fact that when all lights in the room were turned out before the squirrel was started, there was neither hesitancy nor error. Even in the cases where the lights were turned out after the animal had started, a simple hesitancy was the only error presentthe rest of the trip being made as automatically as in the light.

When the maze was rotated $180^{\circ}$ and $270^{\circ}$ respectively, the behavior of the animal was decidedly different. Errors were a frequent occurrence. The animals often ran back to the starting place, hesitating and disturbed on both the forward and the backward runs. The rotation to $270^{\circ}$ seemed provocative of the greatest confusion. The last error after the change was made appeared at the tenth trial. The rotation to $360^{\circ}$, after practise at the two positions just mentioned, produced no errors. There was slight confusion, however, and the time was slower than the fastest perfect time of the earlier tests. This series of trials does not appear in the curve.

These records have not added much in any exact way to our knowledge of the sensory "cues" used by the squirrel in learning and later in automatically running the maze. Those who observed the animals at any time were convinced that the sensory factors operative in the learning process and in the perfected maze habit were other 
Yoakum, Behavior of Squirrels.

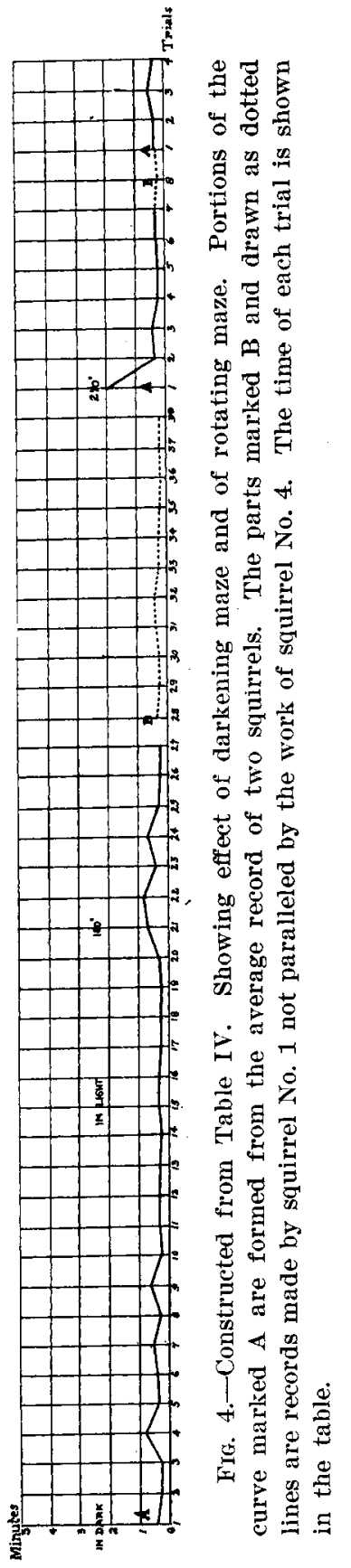


560 Fournal of Comparative Neurology and Psychology.

than those contributed by the distance receptors. These latter seuse organs frequently presented difficulties to the learning process rather than actually assisting it. Such cannot be considered as rigidly proved, but the general and specific behavior of the animals points to such a conclusion.

\section{Tests on Temperature Sense.}

The habit of the squirrels on cold days or whenever the temperature of the room became decidedly lower than usual, of burrowing under shavings, sawdust or cotton, led to an attempt to devise means of testing the temperature sense by the use of the discrimination method. In this connection, the animal's method of covering itself is interesting. The squirrel will draw the shavings, or cotton, up in a pile in one corner of the cage, and will then burrow into it. When finally hidden in the pile, all that is visible is a portion of the tail; if this is drawn aside the tip of the nose and finally the entire head become visible. The little animal thus lies curled up in its nest with the tail as the final addition to its covering.

The temperature test to be described was made in the first place with a view to determining the general features of the temperature sense; in the second place, for the purpose of testing the range and fineness of this sense. The tests as originally planned are not completed. One of the animals was accidentally killed, and the work on the other was stopped by reason of the experimenter's removal to a distant locality. It is probably better to look upon these results as being qualitative and preliminary rather than to consider them. as being standards quantitatively determined.

The apparatus was constructed as follows: Two galvanized iron boxes (A and B, Fig. 5) were made with outside dimensions of $9 \times 9 \times 24$ inches. They were built like square-sided pipes, as shown in the drawing, the inner opening being $5 \times 5$ inches and running the entire length of the box. The space between the outer and inner jackets was two inches deep and entirely enclosed the central cavity with the exception of the ends. This enclosed space was supplied with three vents, an inlet (I), an outlet (O) for the water supply, and an air vent $(\nabla)$ to relieve the pressure when 
YoAkum, Behavior of Squirrels.

$5^{6} \mathrm{I}$

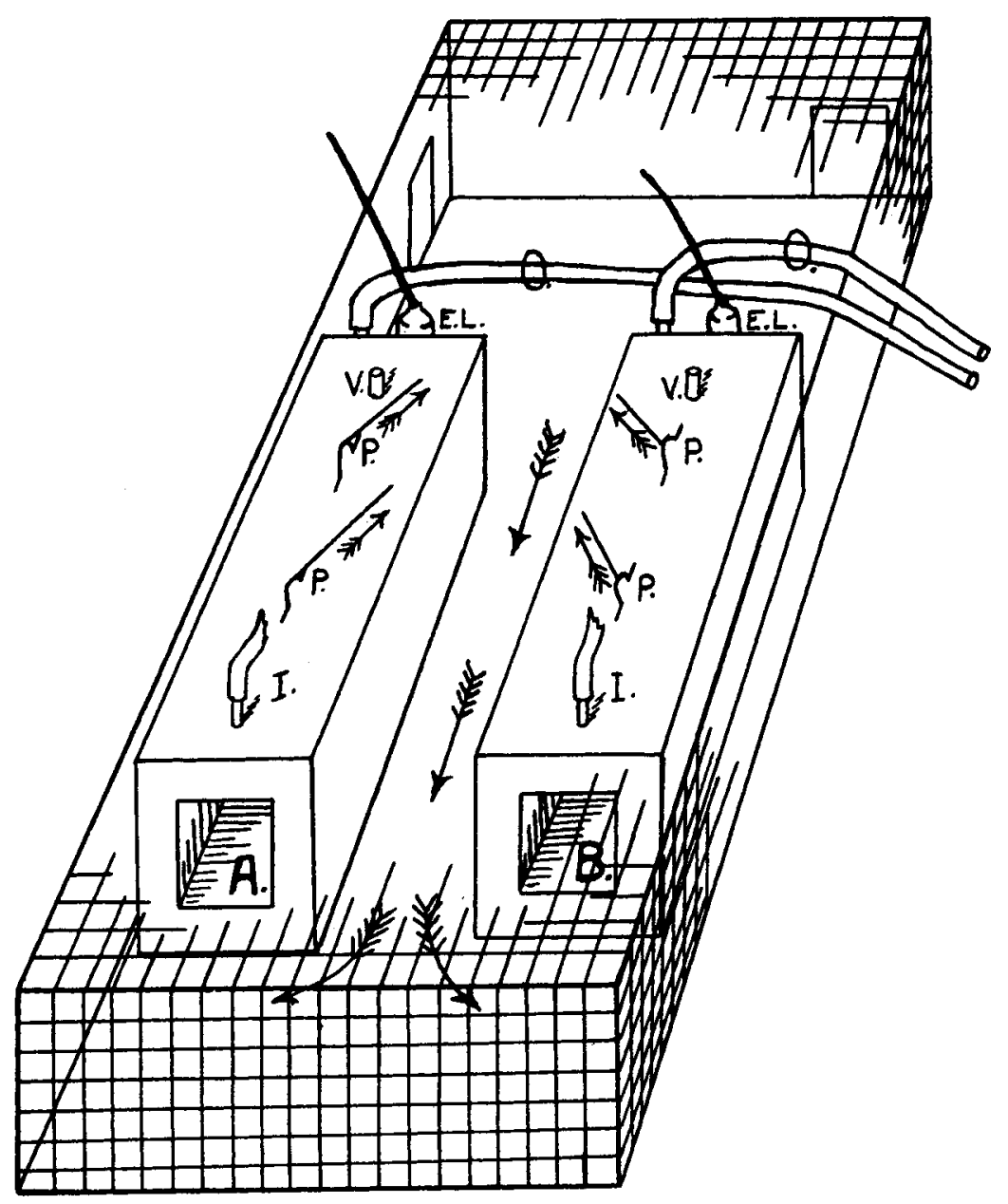

Fig. 5. 
562 Fournal of Comparative Neurology and Psychology.

water was admitted to the vessel, or when the vessel was emptied. This third vent was not needed so long as the circulation of water was constant. The outlet was placed at the bottom of the encircling jacket and brought to a level with the upper part of the box. Arranged thus, it could be used to siphon all the water out, which not only prevented the possibility of rust, but also at the same time afforded the opportunity for beginning work immediately on subsequent days, by eliminating the necessity of heating a large body of cooled water in the jackets.

In the bottom of each of these $5 \times 5$ inch inner passages small cubical pans were sunk flush with the floor to a depth of one inch. These pans served as food receptacles. They were placed near the end farthest from the opening used as an entrance for the animal (thus avoiding any possibility of the use of vision). The back of each box was covered by a ground glass plate, behind which a 16 candle power light (EL) was placed. The boxes were painted throughout a dull black, and every effort exerted to make them absolutely alike. The experimenter found this successful so far as his own discrimination was concerned.

The temperature of these boxes was regulated by forcing hot and cold water of the desired temperature to circulate through them. A triple faucet was used, two vents giving cold and hot water, respectively, and the third so attached that the water from the first two could be mixed and any desired temperature of water obtained. The overflow ran into a sink near by.

The regulation of the temperature was not wholly exact. In the first place, the temperature of the room varied slightly from day to day. The extreme limit of this variation during this series of experiments was 3 degrees. The temperature near the experimental boxes necessarily varied according as the needs of the experiment demanded high or low temperatures. Further, this surrounding air varied considerably during the experiment. It was finally decided that the temperature should be said to be that obtained by a rapidly registering Centigrade chemical thermometer when its glass surface was held against the inner surface of the uniformly heated box, five inches from the mouth or entrance. The mercury of the bulb 
YOAKUM, Behavior of Squirrels.

TABLE V.

Tests on Temperature Discrimination of Squirrels.

\begin{tabular}{|c|c|c|c|c|c|c|c|c|}
\hline \multicolumn{5}{|c|}{ Male Squirrel } & \multicolumn{4}{|c|}{ Female Squirrel } \\
\hline $\begin{array}{c}\text { Series } \\
\text { by days }\end{array}$ & $\begin{array}{l}40^{\circ} \mathrm{C} \text {. } \\
\text { Right }\end{array}$ & $\begin{array}{l}15^{\circ} \mathrm{C} \text {. } \\
\text { Wrong }\end{array}$ & $\begin{array}{l}40^{\circ} \mathrm{C} \\
\text { Right }\end{array}$ & $\left|\begin{array}{c}25^{\circ} \mathrm{C} \\
\text { Wrong }\end{array}\right|$ & $\begin{array}{l}40^{\circ} \mathrm{C} \text {. } \\
\text { ight }\end{array}$ & $\begin{array}{l}25^{\circ} \mathrm{C} . \\
\text { Wrong }\end{array}$ & $\begin{array}{l}40^{\circ} \mathrm{C} \\
\text { Right }\end{array}$ & $\begin{array}{l}30^{\circ} \mathbf{~ C .} \\
\text { Wrong }\end{array}$ \\
\hline $\begin{array}{c}1 \\
2 \\
3 \\
4 \\
5 \\
6 \\
7 \\
8 \\
9 \\
10 \\
11 \\
12 \\
13 \\
14 \\
15^{1} \\
16 \\
17 \\
18 \\
19\end{array}$ & $\begin{array}{r}1 \\
2 \\
3 \\
3 \\
6 \\
3 \\
6 \\
6 \\
4 \\
5 \\
5 \\
4 \\
10 \\
4 \\
2 \\
2 \\
4 \\
3\end{array}$ & $\begin{array}{l}3 \\
3 \\
4 \\
0 \\
1 \\
2 \\
2 \\
0 \\
0 \\
0 \\
0 \\
0 \\
0 \\
0 \\
2 \\
1 \\
0 \\
0\end{array}$ & $\begin{array}{l}4 \\
4 \\
2 \\
4 \\
1 \\
4 \\
2 \\
2 \\
5 \\
4 \\
6 \\
3 \\
2 \\
1 \\
3 \\
2 \\
4 \\
3 \\
3\end{array}$ & $\begin{array}{l}0 \\
0 \\
2 \\
0 \\
3 \\
1 \\
0 \\
1 \\
0 \\
2 \\
0 \\
1 \\
0 \\
0 \\
0 \\
0 \\
0 \\
0 \\
0\end{array}$ & $\begin{array}{r}4 \\
0 \\
4 \\
5 \\
3 \\
5 \\
7 \\
9 \\
3 \\
5 \\
8 \\
4 \\
10 \\
9 \\
10\end{array}$ & $\begin{array}{l}2 \\
6 \\
3 \\
4 \\
6 \\
4 \\
3 \\
0 \\
0 \\
2 \\
1 \\
1 \\
0 \\
0 \\
0\end{array}$ & $\begin{array}{l}5 \\
6 \\
9 \\
9 \\
7 \\
4 \\
6, \\
4 \\
6 \\
5 \\
8 \\
7\end{array}$ & $\begin{array}{l}5 \\
2 \\
2 \\
2 \\
0 \\
3 \\
1 \\
1 \\
1 \\
3 \\
1 \\
3\end{array}$ \\
\hline Totals: & $62^{2}$ & 15 & 59 & 10 & 86 & 32 & 76 & 24 \\
\hline \multicolumn{2}{|c|}{ Percentage. . $80 \%$} & & $85 \%$ & & $73 \%$ & & $76 \%$ & \\
\hline
\end{tabular}

1 At this point a change in conditions was made, see p. 567 .

2 Exclusive of series 15, 16, 17 and 18.

did not come in contact with the side of the box. It was determined by a series of trials that when the temperature thus obtained was $40^{\circ}$ Centigrade, the air in the center of the opening the same distance from the entrance was from $1.5^{\circ}$ to $1.25^{\circ}$ lower. These conditions were kept constant and tested before and during each daily series of experiments.

Flexible rubber tubing was used for making the water connections from the overhead piping. This tubing permitted the raising of one box over the other, which was necessary in order to rule out the position factor. Shifting the large heavy boxes was done by means of a rope and pully $(\mathrm{P})$. The temperature boxes themselves, the space in front of them, the passageway between them, 


\section{Fournal of Comparative Neurology and Psychology.}

and a considerable space behind them, were screened in by wire netting. Sliding wire partitions served to confine the animal in any desired portion of the enclosed space during the adjustment of the apparatus. The passageway between the boxes as they stood in position was five inches wide. The animal entered from behind and passed between the boxes to the open space in front, and there had the choice of turning into the opening of either box.

It will be seen that these tests were made upon few animals. All of the animals, however, were in good condition and the experimenter feels that the results, as far as they go, are representative.

The first set of tests was made upon the male squirrel. The conditions of this test were as follows: Box A, the standard (which contained the food in all the tests), was kept at a temperature of $40^{\circ} \pm 2^{\circ}$ C. Box $\mathrm{B}$, the variable, during the formation of the discrimination habit was kept at the temperature of $15^{\circ} \pm 2^{\circ} \mathrm{C}$. A record of this test is shown in the first three columns of Table $\mathrm{V}$.

After discrimination had become definite, the temperature of the variable box was raised to $25^{\circ} \pm 2^{\circ} \mathrm{C}$. Columns 4 and 5 of the same table show the results of this change.

The second set of tests was made upon a female. In this case, as in the one above, the standard box $\mathrm{A}$ was kept at a temperature of $40^{\circ} \pm 2^{\circ} \mathrm{C}$, but the variable $B$ was kept at a temperature of $25^{\circ} \pm 2^{\circ} \mathrm{C}$. After the association had become definite, the temperature of the variable was raised to $30^{\circ} \pm 2^{\circ} \mathrm{C}$. The latter part of this test (discrimination between $40^{\circ}$ and $30^{\circ}$ ) was not completed, but the work was carried far enough to leave no doubt that the discrimination of this difference was possible. Table $\mathrm{V}$, columns 6, 7, 8 and 9 , show the results of the whole test.

A similar set of tests was made upon three white rats. Table VI shows the records of these animals and the temperatures used.

(a) Discussion of results of tests upon squirrels.-The behavior of the squirrels in this test varies little from recorded descriptions of like experiments in other sensory fields. The "controls" used were such as to eliminate sensory factors other than that of temperature. It may be well to mention in some detail the precautions taken. 
Position was ruled out by reversing the direction of the turn the animal must make to enter the proper box. Our experience in this part of the control is quite similar to Professor Yerkes' description. ${ }^{15}$

TABLE VI.

Tests on Temperature Discrimination of White Rats.

\begin{tabular}{|c|c|c|c|c|c|c|}
\hline \multicolumn{3}{|c|}{ No. 1} & \multicolumn{2}{|c|}{ No. 2} & \multicolumn{2}{|c|}{ No. 3} \\
\hline $\begin{array}{c}\text { Series } \\
\text { by days }\end{array}$ & $\begin{array}{l}40^{\circ} \mathrm{C} . \\
\text { Right }\end{array}$ & $\begin{array}{l}24^{\circ} \mathrm{C} . \\
\text { Wrong }\end{array}$ & $\begin{array}{l}40^{\circ} \mathrm{C} . \\
\text { Right }\end{array}$ & $\begin{array}{c}24^{\circ} \mathrm{C} . \\
\text { Wrong }\end{array}$ & $\begin{array}{l}40^{\circ} \mathrm{C} \text {. } \\
\text { Right }\end{array}$ & $\begin{array}{l}24^{\circ} \mathrm{C} . \\
\text { Wrong }\end{array}$ \\
\hline $\begin{array}{r}1 \\
2 \\
3 \\
4 \\
5 \\
6 \\
7 \\
8 \\
9 \\
10 \\
11 \\
12 \\
13 \\
14 \\
15 \\
16 \\
17 \\
18\end{array}$ & $\begin{array}{r}3 \\
3 \\
2 \\
3 \\
2 \\
2 \\
3 \\
2 \\
6 \\
7 \\
2 \\
2 \\
9 \\
9 \\
10 \\
10\end{array}$ & $\begin{array}{l}3 \\
3 \\
4 \\
2 \\
1 \\
0 \\
2 \\
2 \\
2 \\
1 \\
0 \\
3 \\
2 \\
0 \\
0 \\
0\end{array}$ & $\begin{array}{r}3 \\
3 \\
4 \\
3 \\
6 \\
4 \\
5 \\
4 \\
2 \\
3 \\
6 \\
5 \\
5 \\
5 \\
9 \\
9 \\
10 \\
10\end{array}$ & $\begin{array}{l}3 \\
3 \\
2 \\
3 \\
2 \\
0 \\
0 \\
3 \\
4 \\
1 \\
1 \\
0 \\
0 \\
0 \\
0 \\
0 \\
0 \\
0\end{array}$ & $\begin{array}{r}\mathbf{3} \\
\mathbf{4} \\
\mathbf{4} \\
\mathbf{3} \\
\mathbf{4} \\
1 \\
4 \\
\mathbf{3} \\
4 \\
4 \\
\mathbf{5} \\
6 \\
4 \\
5 \\
10 \\
\mathbf{9} \\
10 \\
\mathbf{1 0}\end{array}$ & $\begin{array}{l}3 \\
2 \\
3 \\
3 \\
3 \\
2 \\
1 \\
2 \\
2 \\
1 \\
2 \\
1 \\
2 \\
0 \\
1 \\
0 \\
0 \\
0\end{array}$ \\
\hline Totals. . & 75 & 25 & 96 & 22 & 93 & 27 \\
\hline \multicolumn{2}{|c|}{ Percentages...75\% } & & $81 \%$ & & $77 \%$ & \\
\hline
\end{tabular}

It was found impossible to eliminate the position factor to the point where it became non-operative. This failure to rule out position was used in the latter part of the series as a semi-control test. Going twice or three times into the box in one position was sufficient to establish a preference in favor of that side. Changing the rightleft relation of the boxes at this stage constituted a severe test, both of the temperature association and of the squirrel's patience. No failures to choose correctly between the boxes are recorded at the stage where this test was tried.

${ }^{15}$ The Dancing Mouse, The Macmillan Co., '07, p. $91 \mathrm{ff}$. 
As has already been mentioned, all visual difference between the boxes was eliminated. The boxes were of the same size, both were painted black and closed at the back by ground glass windows. Behind these windows, $16 \mathrm{c}$. p. electric lights were placed in order to prevent the possibility of unequal lighting (at times these lights were interchanged). The food boxes were sunk into the bottom of the passage way, and nut hulls and the kernels used for food could not be seen from the upper part of the entrance. To prevent any possibility of this, however, both food boxes were partly filled with empty nut hulls, and toward the close of a series, with whole nuts and pieces of nuts. In a control test, both lights behind the boxes were turned off entirely, leaving both boxes in total darkness; finally, first one light and then the other was turned off to determine the firmness of the association.

Smell was eliminated by rubbing the side and bottom of the fiveinch passage way with nut kernels and with other aromatic substances. Food was frequently placed in both food boxes, when the discrimination had been established, to test thoroughly the absence or presence of smell associations as well as visual.

In order to be certain that all the factors other than temperature were alike in both boxes, the box which was made the standard on one day $\left(40^{\circ}\right)$ was used as the variable on the succeeding day. This alteration was not constant, $i$. e., not made every other day. It was feared that even this regularity might be learned by the squirrel, so that the change of the standard temperature from one box to another was made quite frequently in the midst of a single day's series.

To prevent discrimination in the runway on any basis whatever, the sides were covered with asbestos. It was not particularly intended that discrimination on the basis of temperature should not take place here, but in order to eliminate secondary criteria, it seemed better to eliminate differences in temperature as well.

After the association had been formed, an effort was made to determine how the squirrel detected the temperature of the box. This was very incompletely done, for the reason that it was desired to confuse the animal as little as possible in order that the later experiments might proceed immediately. Asbestos pieces were prepared 
to fit snugly over the front lower edge of the entrance. These were placed over both boxes and thus shut out all temperature discrimination by contact, thus forcing the animal to depend upon the air in the entrance to the tunnel. The effect is shown in the records of the first set of tests, series 15, 16, 17 and 18, Table V.

The squirrel was plainly confused, which he showed by sniffing the air and testing each box once or even twice before entering. He soon learned, however, to depend upon the air at the entrance of the box in deciding which box to enter. It seems quite possible that under the first set of conditions, the squirrel was discriminating partly by actual contact with the metal of the box and partly by means of the air at the entrance.

(b) Discussion of results of tests upon white rats.-Table VI shows the work of three white rats on temperature discrimination. The method used was slightly different from that pursued with the squirrels. The rats seemed so uncertain and irregular in their early tests, that it was practically necessary to develop a position habit. Such a habit was accordingly developed and then broken. The rat learned to find the food in one box by position, then the position was changed and he was compelled to learn a new position. To the observer at least the earlier stages of the learning process seemed to be much more easily detected by this method than by the method used in the experiments upon the squirrels.

\section{Conclusion.}

1. In the solution of the problems placed before the squirrel in the series of experiments, it is shown that the squirrel learns by the trial and error method. His learning curves are in the main similar to the curves representing the learning processes in the white rat.

2. The greater irregularities in the curves obtained from the squirrel may, perhaps, be explained on the basis of emotional factors that are more prominent in these animals than in the rat. The greater sensivity to emotional disturbances seems to be due to the fact that the distance receptors play a larger rôle in the life of the squirrel than in the rat. Experimental proof of this seems possible.

3. Successful training in certain problems is highly prejudicial 


\section{Tournal of Comparative Neurology and Psychology.}

to the further training of the same animal in problems which present a large number of similar conditions. Different methods of opening the same problem box constitute such unfavorable conditions. A latch problem box and the maze, for example, do not present enough identical conditions to interfere with the learning process of the one when the other has been learned first.

4. The grey squirrel and the white rat can form associations upon the basis of a temperature sense. Actual tests show that the squirrel can discriminate between two boxes when they differ in temperature by $25^{\circ}$. In the case of one animal tested, a difference of $10^{\circ}$ in the temperature of the box was found discriminable. Further tests with a more accurate apparatus would in all probability show that the discriminable difference in temperature may be much less. The experiments upon the white rats show that a difference of $16^{\circ}$ is easily discriminated.

5. Incentives which may be used easily in further investigations with the squirrel are: hunger, disagreeable odors and tastes (bad nuts, onions, etc.), gnawing impulses, and love of exercise and greater freedom. This last incentive is especially strong in the squirrel.

The ability of the squirrel to detect an edible nut from a faulty one probably contains the sense, or senses, in which the keenest discriminative power of the squirrel is reached. 